\title{
Cantiga de Ceilão, com Jorge de Sena em Santa Bárbara
}

Kenneth David Jackson ${ }^{1}$

RESUMO: Um estudo de uma cantiga em crioulo indo-português da comunidade de descendentes de portugueses da costa oriental do Sri Lanka, gravada pelo autor em pesquisa de campo, incluindo uma orientação à história e persistência da língua portuguesa crioula na ilha. Relata a origem do poema "Cantiga de Ceilão" de Jorge de Sena e a relevância dos versos para o pensamento e a situação do poeta, separado da língua portuguesa.

PALAVRAS-CHAVE: Ceilão. Crioulo. Cantiga. Comunidade. Descendentes.

\section{“CANTIGA FROM CEYLON” WITH JORGE DE SENA IN SANTA BARBARA}

ABSTRACT: A study of a cantiga in Indo-Portuguese creole from a community of descendants of Portuguese on the East coast of Sri Lanka, recorded by the author during fieldwork, including a survey of the history and persistence of the Portuguese creole language on the Island. The study addresses the origin of the poem "Cantiga from Ceylon" by Jorge de Sena and its relevance to the thought and situation of the poet, separated physically and culturally from the Portuguese language.

KEYWORDS: Ceylon. Creole. Cantiga. Community. Descendants.

"Mara mutem fundu minhe vida par tira Rue nuga largu minhe morte par leve"

"O mar não é tão fundo que me tire a vida Nem há tão larga rua que me leve a morte."

A chegada inesperada da cantiga de Ceilão à casa de Jorge de Sena em Santa Bárbara representa um caso insólito de intertextualidade, sendo uma reação a versos cantados ao vivo num crioulo português daquele mesmo ano que deram início a um diálogo através dos séculos da expansão da língua portuguesa no Oriente e a uma meditação sobre a situação atual dessa língua e sua cultura no mundo.

Para Jorge de Sena, esses versos de música da comunidade de "Burghers portugueses", descendentes de portugueses que viviam isolados na costa leste do Sri Lanka, previamente Ceilão, desde o século XVI, eram testemunhas de vida e identidade portuguesas perdidas no tempo, de um estado de exílio permanente que ressoou com a pena que JS sentiu quando da sua separação de Portugal, em agosto de 1959. Abandonou o regime salazarista e se refugiou no Brasil, para nunca voltar a morar em sua casa em Lisboa. No poema "O

\footnotetext{
${ }^{1}$ Professor de literatura luso-brasileira e Diretor de Estudos de Português na Graduação da Yale University. Doutorou-se com Jorge de Sena na Universidade de Wisconsin. Autor de Machado de Assis: A Literary Life (Yale, 2015), Adverse Genres in Fernando Pessoa (Oxford, 2010), De Chaul a Batticaloa: As Marcas do Império Marítimo Português na Índia e no Sri Lanka (Mar de Letras, 2005) e Sing Without Shame (John Benjamins, 1990), entre outros.
} 
ecumenismo lusitano ou a dupla nacionalidade" (1969), o poeta, conversando com duas senhoras numa viagem a Roma, explicou que era brasileiro. Uma das senhoras, filha de imigrantes portugueses no Brasil, exclamou: “Ah, naturalizado, não é brasileiro!” E outra mulher morena, uma portuguesa dentro de “opulentas peles," exclamou ao ouvir que o poeta era também português, "-Brasileiro naturalizado? Ah, não é português" e voltou-lhe as costas. O exílio o privou de duas nacionalidades e o deixou professor no Brasil, nos Estados Unidos e em viajante pelo grande mundo, um não-português, não-brasileiro e não-americano suspeito.

Os versos crioulos falam de mar, morte e ruas - temas e realidades centrais na poesia de JS e importantes ao pensamento e existência do poeta. Comparou implicitamente o exílio transatlântico às viagens pelos mares do sul da Ásia de Fernão Mendes Pinto, na última metade do século XVI, ao escolher como título para o livro associado ao seu regresso à Europa, em 1969, Peregrinatio - o que repete o título do romance-depoimento de Mendes Pinto, a Peregrinação (1614), cheia de aventuras fantásticas e às vezes demoníacas de um heróivítima das suas variadas circunstâncias. No poema "Longitude", de Coroa da Terra, JS já fala de ruas alegóricas e revoltosos:

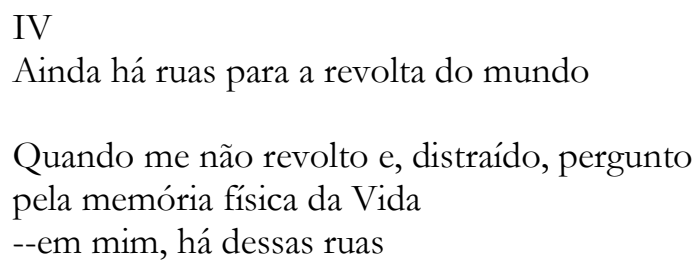

São ruas interiores que simbolizam a sua partida, a sua diferença do mundo e a resistência contra a presença habitual dos caminhos da vida. Ao andar por essas ruas, o poeta resiste à morte e lembra-se da revolta contra o exílio existencial. Reconhece que os versos crioulos também foram cantados numa terra de exílio, inclusive da própria língua da qual se originaram. Desta maneira, mares e ruas ressoam na poesia e na imaginação, trazidos à consciência pelas canções inesperadas, vindas de longe, de uma morte viva no espaço e no tempo.

\section{As Cantigas do Ceilão (Sri Lanka)}

A ortografia extremamente variável, a fala de gerações que não entenderam bem a língua, um processo de mudança indicado por palavras quebradas na metade, referências crípticas ou sem sentido, versos em que se pode entender o significado das palavras, mas não 
do conjunto - são todos fatores que parecem indicar uma língua ou dialeto, em vias de extinção, de um povo lutando para preservar os costumes de séculos passados. Mas, não obstante, a cultura e a etnia burgher criadas pela mestiçagem ainda contribuem de uma maneira importante para a expressão portuguesa no mundo.

Capitão João Ribeiro, cativo no Ceilão no século XVII, relata a construção dos fortes e a presença de uma povoação portuguesa no começo do ano 1624:

Batecalou, fortaleza posta em uma ponta da terra, que cobria huma bahia, capaz de recolher navios de alto bordo, era hum quadrado de quatro baluartes ao antigo, com doze peças de ferro, e a guarnecia um capito; e de presidio cincoenta soldados, hum condestável, vinte moradores, capello, Igreja, casa de mantimento e munições. (RIBEIRO, 1836, p. 33)

A comunidade burgher portuguesa de Batticaloa, hoje organizada na União Católica Burgher, constitui um dos maiores grupos de famílias que preservam a língua e a música crioulas nesta isolada cidade portuária, como remanescência de uma cultura que dominou a sociedade da ilha por centenas de anos. Esses fortes continuaram em mãos dos portugueses até 1638-39, quando chegaram os holandeses. Paul Pieris explica a implantação da língua portuguesa como política de colonização e de miscigenação. Não só era a presença portuguesa racialmente misturada, mas as viúvas e filha solteiras, que mais tarde foram dadas aos soldados holandeses, passaram a constituir uma classe de cidadãos de origem europeia mista chamados burghers. A estes casamentos também se atribui o domínio da língua portuguesa, em casa e na religião, durante o período holandês. D. E. Hettiaratchi chamou a atenção para eles, em 1969, num artigo sobre as contribuições portuguesas para a língua cingalesa:

Batticaloa é a mais rica fonte de português do Ceilão. Fomos informados que nada menos que trezentas famílias ainda falam português [...] Como viviam numa área de fala tâmil, a maioria sabe tâmil, mas alguns também falam cingalês. A União Católica Burgher reúne estas pessoas e disseramnos que se fala português na Reunião Geral Anual dessa União [...]. Os membros da comunidade portuguesa de Batticaloa têm muito orgulho na sua cultura e estão interessados em preservar a sua língua. (HETTIARATCHI, 1969, p. 747-748)

A música crioula perdurou juntamente com a língua e a religião, segundo comenta Tavares de Melo, numa descrição da situação dos burghers portugueses em fins do século XIX: É moda em Ceylão de todos os descendentes, burghers como se lhes chama lá, passarem por descendentes hollandezes, de quem, salvo rara exceção, não possuem o nome, cor, nem mesmo a língua que ninguém aqui sabe falar! usando pelo contrário todos em família o português basso - crioulo português. Porém taxam de burghers ou micos (mecânicos) uns 
humildes profissionais, em geral iletrados e pretos, que às vezes nem appellidos portugueses possuem!.... O próprio termo português é aplicado à mais baixa classe social - sapateiros, etc. (PIERIS, 1912, p. 71)

A performance de uma cantiga é sempre ocasião alegre, com festas de dança, em noites de luar, ao som das notas suaves, usualmente com dois violinos, duas violas, um tamborim, ferrinhos e uma bandeirinha.

Percebe-se a característica africana do povo e no estilo musical da kaffrinha, como comenta Smith (SMITH, 1977, p. 30). O folclore crioulo português de África sem dúvida que foi levado para a Ásia nas naus portuguesas. A contribuição africana nos textos crioulos folclóricos na Ásia é confirmada pela evidência do Sri Lanka, uma vez que a presença de soldados africanos e músicos cafres é mencionada por Tavares de Melo, C. M. Fernando e outros. Dalgado recolheu duas estrofes de versos populares (chicotas) que se referem a negros africanos nas praças do Norte, que incluíam Diu e Damão:

Que lá lé, que lá lé

Que quer dizer nigarinha na cozinha?

Senhor, com su prepar de almoço

Folhas entre folhas, Dopina

Folhas de safrona

Ai! Aqui nesta erancha, Senhor,

Maria é uma cafrona. (DALGADO, 1906, p. 210)

António Moniz reproduz letras de músicas e melodias interpretadas tradicionalmente pelos negros, no dia da festa de São Benedito, em Damão:

Seus beiços cumprido

Seus olhos torcido

Rosto de rabana

Tem cafre de Inhabano. (MONIZ, 1925, p. 572).

Da mesma maneira, há conteúdo asiático nas cantigas do Ceilão, com referências a estilos de cabelo das senhoras "em forma semi-espherica com ponta grande por traz da cabeça” (SCHUCHARDT), profissões e vocabulário konkani:

Trie maiatoeatte

Roppa já lavva

Oen diya attardie

Dieya Sastafara

Jada Saguvaatie

Lansoe de Estrala (JACKSON, 1990, p. 145)

As cantigas incluem imagens de noivas, 
Fulla mugarien bastiana

Cherroe de premaroe

além de referências geográficas:

Eau tanda Bengal

Riva de oen cheecha

Jaffoi todo etarra

Tarra Poodoocherry (JACKSON, 1990, p. 150)

Um disco comercial de música kafferinga, intitulado "Baila Session in Sri Lanka", lançado em 1975, torna evidente a integração da cultura burgher na música contemporânea. Um desenho de capa ilustra uma festa com participantes vestidos à moda ocidental, com uma garrafa de arrack na mesa, retratos de antepassados na parede, um conjunto com violino, bandeirinha e um tambor de pele segurado na mão. A intenção é de sugerir um ar de decadência, com cigarros e copos de álcool. A comunidade burgher da costa oriental da ilha não tardará a perder a sua identidade cultural por causa da migração de jovens, emigração das famílias e o predomínio do tâmil como língua principal e do inglês, herança administrativa e urbana.

A sobrevivência da tradição oral na vida da comunidade no Ceilão, muito depois do contato com os portugueses, serve para documentar o papel dos textos literários como veículo de manutenção e continuidade de um sistema cultural. As canções são textos literários, relacionados ao romance hispânico, à poesia popular e religiosa, ao teatro medieval e ao conto folclórico. Romances narrativos relacionados com os ciclos carolíngio e arturiano constituem um elemento proeminente; o teatro medieval português, levado pelas naus da carreira da Índia, é outro género literário que se reflete nas tradições indo-portuguesas, além de peças devocionais, morais e de milagres, que eram comuns no Ceilão. Sebastião R. Dalgado considerava o português do Ceilão o dialeto crioulo mais importante da Ásia pela sua vitalidade e pela influência do seu vocabulário na língua cingalesa:

Antes de mais, o dialecto português, que é o mais importante de todos os crioulos portugueses até a data é de grande vitalidade; segundo, a intromissão na dicção cingalesa, que está além disso abundantemente abastecida de uma multidão de termos portugueses. (DALGADO, 1936, lxxi-lxxii)

A documentação e coleção da poesia crioula vêm complementar o interesse histórico dos portugueses e da língua portuguesa no Oriente, a partir provavelmente do Dialecto português de Ceylão (1900) de Dalgado e do Esquisse d'une dialectologie portugaise (1901) de José Leite de Vasconcelos. O linguista austríaco Hugo Schuchardt publicou uma variante da 


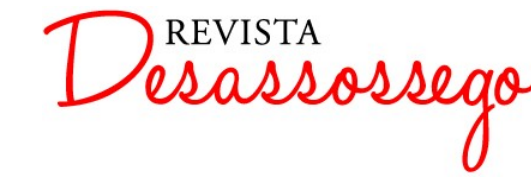

DESASSOSSEGO 21 | DEZ/2019 | ISSN 2175-3180

DOI: http://dx.doi.org/10.11606/issn.2175-3180.v11i21p34-42

“cantiga de Ceilão" na Zeitschrift Für Romanische Philologie:

Esta rua tão cumprido, jambalon

Por pobre passageiro

Por passar todo mundo, jambalon

Com meo pobre companheiro (SCHUCHARDT, 1889b)

Dando seguimento dos estudos linguísticos e recolha de textos da década de 1970, de Ian R. Smith e o autor deste ensaio, o recente projeto da Universidade de Lisboa, "Documentation of Sri Lankan Portuguese" sob a orientação de Hugo Cardoso tem acumulado um extenso banco de dados em trabalho de campo em 2017-18 nas cidades de Batticaloa e Trincomalee. Esse projeto ambicioso reconhece a importância do crioulo e das comunidades de descendentes na era da lusofonia. Nas gravações do projeto, observa-se a performance na comunidade ainda hoje de quadras populares com variantes, às vezes com uma total falta de contexto, mas mantendo vivas as "cantigas" seculares cantadas pelo povo burgher.

\section{Uma visita a Santa Bárbara}

Logo depois de voltar de uma viagem de pesquisa de campos no Sri Lanka, visitei o poeta Jorge de Sena em Santa Bárbara, em março de 1974, apenas um mês antes da "Revolução dos Cravos" em Portugal. Desde 1965 estudara com Jorge de Sena na Universidade de Wisconsin-Madison, onde orientou a minha tese de doutoramento. Desde que mudou para Santa Bárbara em 1970, visitava regularmente a casa na Califórnia na categoria de ex-aluno muito próximo à família Sena. Eu estivera por um mês no Ceilão, em dezembro-janeiro de 1973-74, onde continuava a pesquisar a língua crioula e textos folclóricos de descendentes de portugueses, residentes no porto de Batticaloa, na costa leste da ilha. Numa sessão na sala, à noite, onde costumava haver visitas e conversação intelectual, fiz-lhe ouvir algumas gravações de música e mostrei-lhe versos, recolhidos na pesquisa junto aos burghers portugueses.

\section{E chegam-me do fundo de Ceilão e do tempo} por mão amiga que os encontrou ainda vivos.

O poema "Cantiga do Ceilão" teve sua origem nessa gravação musical da cultura portuguesa implantada na Ásia nos séculos XVI e XVII, da qual o crioulo português de Sri Lanka (Ceilão) é um dos exemplos mais persistentes. A construção do forte em Batticaloa a partir de 1624 reuniu portugueses, lascarins, africanos da costa oriental e outros colonos, segundo o relato seiscentista do Capitão João Ribeiro (RIBEIRO, 1836). As cantigas sempre 
comunicavam a energia, o espírito comunitário e o prazer despreocupado da cultura indoportuguesa.

Distâncias de oceanos os conduશiram como bábito de serões e vigílias.

Esse povo animava-se com o ritmo e a melodia da cafrinha tradicional por trezentos e cinquenta anos.

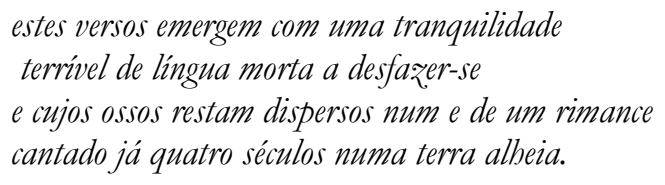

Se a minha visita tivesse demorado mais um mês, talvez o poema fosse diferente por causa da Revolução, mas sendo de Março, comunicava-nos a fragmentação da língua portuguesa num mundo de exílio, ainda colonial, de um Babel camoniano, que era o mundo em que Jorge de Sena vivia. Os versos ecoaram num espaço íntimo para o poeta português, que vivia na Califórnia entre arquipélagos de língua portuguesa, falada apenas por alunos, emigrantes ou exilados, com a memória de um Portugal distante:

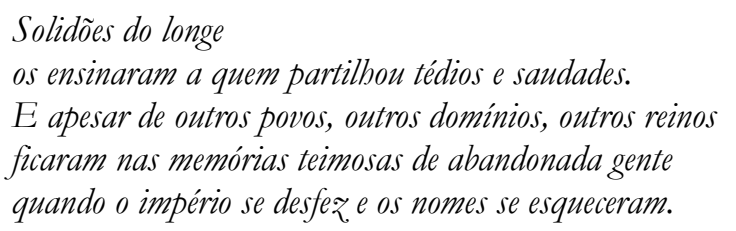

O poema resume todo um período de exílio e de resistência contra o Salazarismo e o Marcelismo.

\title{
Nesta noite do mundo a abater-se sombria sobre um Portugal que os deuses já cegaram
}

Quando o poema saiu, postumamente, em 1979 (datado 23/3/74), surpreendeu-me, pois lembrei-me que ao ouvir as músicas e ler os textos aquela noite em casa, Sena apenas tomara notas sobre dois versos, cantados sem acompanhamento, depois convertidos em epígrafe:

\author{
Mara mutem fundu minhe vida par tira \\ Rue nuga largu minhe morte par leve. \\ 'O mar não é tão fundo que me tire a vida \\ Nem há tão larga rua que me leve a morte' - trad. J. S.].
}

Nada havia a indicar que esse momento desse origem a uma ideia ou uma intenção poética, ou de profunda meditação sobre o mundo da língua portuguesa, a ser convertida em poema. Assim, a "Cantiga" permite-nos observar de perto o método criativo de JS em ação. 


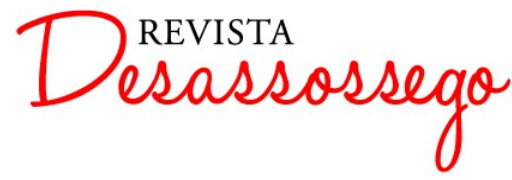

DESASSOSSEGO 21 | DEZ/2019 | ISSN 2175-3180

DOI: http://dx.doi.org/10.11606/issn.2175-3180.v11i21p34-42

Os versos, até a voz da senhora que cantava, gravada ao vivo na fita cassette, pareciam sair de um espaço marítimo infinito, vOz da dissolução da cultura portuguesa na Ásia e da sua dispersão no vasto mundo das navegações e do exílio:

estes versos portugueses leio como se lêem as pedras no fundo de água turva e remexida.

Jorge Fazenda Lourenço reconhece no confronto dos textos

um exemplo sui generis de heteroglossia, uma vez que "Os versos-mote fazem parte da recolha dos diferentes creoulos portugueses" (40 Anos, 199) do Ceilão. A transcrição do poema permitiria visualizar melhor estas diferentes componentes da citação, para além de conter informações sobre a origem desses versos miscigenados (LOURENÇO, 1998, 224).

É preciso lembrar-se, portanto, que ambas as versões pertencem à língua portuguesa, uma versão, no caso, havendo sido mudada com e pelo tempo, da maneira como as línguas em contato sempre mudam, sobretudo quando isoladas da sua fonte. Precisamente o impacto que fizeram essas cantigas sobre Jorge de Sena advém de elas serem também português, como dizia, num país esquecido e entre gente dissolvida. Nos versos, como num espelho mágico, o poeta vê o seu destino refletido e o destino da língua portuguesa no mundo.

Ao conhecer esses versos insólitos, depois de anos passados no exílio, o poeta associa a morte secular da língua com a dispersão daquilo que foi e que poderia ter sido Portugal no mundo, e que ele defendia como intelectual, poeta e professor, com uma voz que se perdia também nos mares de Santa Bárbara.

Falam de morte a que profundas não bastam

e de ruas estreitas em que ela não cabe ou passa.

Fundos de mar e ruas como a vida sabe

se perdida em si mesma, presa por um fio

a um país esquecido e que se esquece ao longe,

palavra a palavra, por gente dissolvida.

Mas na resistência dessa voz do Ceilão contra o destino e o tempo, contra a distância e o esquecimento, contra a própria morte, o poeta percebia uma "pequenina luz." É a determinação desse povo do Ceilão a vencer o tempo e os mares, de andar por essas ruas, a coragem de manter viva essa língua, contra tudo e todos, e contra a própria morte, que revitaliza o poeta ao ouvir as palavras vindas de longe e que justificam o poema. Dir-se-ia que o escreveu para desafiar a morte, que levaria o nosso poeta uns escassos quatro anos depois de composta a "Cantiga," sua, mas também cantiga do destino do caminho marítimo, ao qual o poeta pertence, reconhecidamente, e da própria língua em que escreve. São as cantigas de uma biografia poética, uma biografia de estar-se no vasto mundo da língua 
portuguesa em dissolução, mas ainda e apesar de tudo um símbolo da sua permanência e resistência, a revolta contra o destino e o exílio que era a própria vida do poeta Jorge de Sena. Poderíamos ler como pressentimento da "Cantiga do Ceilão" a quadra com que termina o poema "NEL MEZZO DEL CAMIN...":

E nem morte nem vida podem mais do que apagarem sem deixar sinais. (30/1/62).

\section{OBRAS CITADAS}

DALGADO, Sebastião R. Dialecto indo-português de Ceylão. Lisboa: Imprensa Nacional, 1900a. HETTIARATCHI, D.E. Influence of the Portuguese on the Sinhalese Language. Journal of the Royal Asiatic Society, Ceylon (1965) 9:2.229-238. Trad. SENA, Isabel de.

JACKSON, Kenneth David. Sing Without Shame: Oral Traditions in Indo-Portuguese Creole Verse. Amsterdam and Macau: John Benjamins, Cultural Institute of Macau, 1990.

LOURENÇO, Jorge Fazenda. A Poesia de Jorge de Sena: testemunho, metamorfose, peregrinação. Paris: Gulbenkian, 1998, 287-288.

PIERIS, Sir Paulus E. "Ceylão Portuguez no Princípio do Século XVIII." O Oriente Português (Goa) 9:3-4, 61-89. Trad. SENA, Isabel de.

PIERIS, Sir Paulus E. Ceylon: The Portuguese Era. 2 vols. Colombo: Ceylon Apothecaries. 191314. Trad. SENA, Isabel de.

RIBEIRO, João. Fatalidade Histórica da Ilha de Ceilão. 1685. Lisboa: Academia das Ciências, 1836. SENA, Jorge de. 40 Anos de Servidão. Lisboa: Moraes, 1978.

SCHUCHARDT, Hugo. Beiträge zur Kenntnis des cfreolischen Romansich. VI. Zum Indoportugiesischen vonb Mahé und Cannanore. Zeitschrift Für Romanische Philologie (1889b.) 13.516-24.

SMITH, Ian R. 1977. "Sri Lanka Creole Portuguese Phonology.” Diss Cornell U.

TAVARES DE MELO, B.C. "FolkLore Ceilonense.” Revista Lusitana (1907) 10.102-121, 311-20; (1908) 11.164-175. Trad. SENA, Isabel de.

VASCONCELOS, J. Leite de. Esquisse d'une dialectologie portugaise. 2.a ed. Maria Adelaide Valle Cintra, ed. Lisboa: Centro de Estudos Filológicos, 1970. 